\title{
Potential in the elimination of cancer cells through synchrotron radiation: $A$ hartree-fock methods analysis protonated rhodochrosite crystal
}

\author{
Ricardo Gobato ${ }^{1}$, Marcia Regina Risso Gobato ${ }^{2}$, Alireza Heidari ${ }^{3 *}$ and Abhijit Mitra ${ }^{4}$ \\ ${ }^{1}$ Laboratory of Biophysics and Molecular Modeling Genesis, State Secretariat of Education of Parana, 86130-000, Parana, Brazil \\ ${ }^{2}$ Green Land Landscaping and Gardening, Seedling Growth Laboratory, 86130-000, Parana, Brazil \\ ${ }^{3}$ Faculty of Chemistry, California South University, 14731 Comet St. Irvine, CA 92604, USA \\ ${ }^{4}$ Department of Marine Science, University of Calcutta, 35 B.C. Road Kolkata, 700019, India
}

\begin{abstract}
The rhodochrosite $\left(\mathrm{MnCO}_{3}\right)$ shows complete solid solution with siderite $\left(\mathrm{FeCO}_{3}\right)$, and it may contain substantial amounts of $\mathrm{Zn}, \mathrm{Mg}$, $\mathrm{Co}$, and $\mathrm{Ca}$. There is no precedent in the literature on the treatment of tumor tissues by eliminating these affected tissues, using rhodocrosite crystals in tissue absorption and eliminating cancerous tissues by synchrotron radiation. The studies that are found are the research papers of this team. Through an unrestricted Hartree-Fock (UHF) computational simulation, Compact effective potentials (CEP), the infrared spectrum of the protonated rhodochrosite crystal, $\mathrm{CH}_{19} \mathrm{Mn}_{6} \mathrm{O}_{8}$, and the load distribution by the unit molecule by two widely used methods, Atomic Polar Tensor (APT) and Mulliken, were studied. The rhodochrosite crystal unit cell of structure $\mathrm{CMn}_{6} \mathrm{O}_{8}$, where the load distribution by the molecule was verified in the UHF CEP-4G (Effective core potential (ECP) minimal basis), UHF CEP-31G (ECP split valance) and UHF CEP-121G (ECP triple-split basis). The largest load variation in the APT and Mulliken methods were obtained in the CEP-121G basis set, with $\delta=2.922$ e $\delta=2.650$ u. a., respectively, being $\delta_{\mathrm{APT}}>\delta_{\mathrm{Mulliken}}$. The maximum absorbance peaks in the CEP-4G, CEP-31G and CEP-121G basis set are present at the frequencies $2172.23 \mathrm{~cm}^{-1}$, with a normalized intensity of $0.65 ; 2231.4 \mathrm{~cm}^{-1}$ and 0.454 ; and $2177.24 \mathrm{~cm}^{-1}$ and 1.0, respectively. An in-depth study is necessary to verify the absorption by the tumoral and non-tumoral tissues of rhodochrosite, before and after irradiating of synchrotron radiation using Small-Angle X-Ray Scattering (SAXS), Ultra-Small Angle X-Ray Scattering (USAXS), Fluctuation X-Ray Scattering (FXS), Wide-Angle X-Ray Scattering (WAXS), Grazing-Incidence Small-Angle X-Ray Scattering (GISAXS), Grazing-Incidence Wide-Angle X-Ray Scattering (GIWAXS), Small-Angle Neutron Scattering (SANS), Grazing-Incidence Small-Angle Neutron Scattering (GISANS), X-Ray Diffraction (XRD), Powder X-Ray Diffraction (PXRD), Wide-Angle X-Ray Diffraction (WAXD), Grazing-Incidence X-Ray Diffraction (GIXD) and Energy-Dispersive X-Ray Diffraction (EDXRD). Later studies could check the advantages and disadvantages of rhodochrosite in the treatment of cancer through synchrotron radiation, such as one oscillator crystal. Studying the sites of rhodocrosite action may lead to a better understanding of its absorption by healthy and/or tumor tissues, thus leading to a better application of synchrotron radiation to the tumors to eliminate them.
\end{abstract}

\section{Introduction}

The rhodochrosite $\left(\mathrm{MnCO}_{3}\right)$ shows complete solid solution with siderite $\left(\mathrm{FeCO}_{3}\right)$, and it may contain substantial amounts of $\mathrm{Zn}, \mathrm{Mg}$, Co, and $\mathrm{Ca}$. The electric charge that accumulates in certain solid materials, such as crystals, certain ceramics, and biological matter such as bone, DNA and various proteins in response to applied mechanical stress, phenomenon called piezoelectricity [1-12].

Through an unrestricted Hartree-Fock (UHF) computational simulation, Compact effective potentials (CEP), the infrared spectrum of the protonated rhodochrosite crystal, $\mathrm{CH}_{19} \mathrm{Mn}_{6} \mathrm{O}_{8}$, and the load distribution by the unit molecule by two widely used methods, Atomic Polar Tensor (APT) and Mulliken, were studied. The rhodochrosite crystal unit cell of structure $\mathrm{CMn}_{6} \mathrm{O}_{8}$, where the load distribution by the molecule was verified in the UHF CEP-4G (Effective core potential (ECP) minimal basis), UHF CEP-31G (ECP split valance) and UHF CEP-121G (ECP triple-split basis).

The Figure 1 is one photography the Rhodochrosite stone from Cangwu, China. Rhodochrosite Paragenesis, Apatite (brownish),
Fluorite (purple), Quartz (colorless) and some tiny pyrite cubes from Cangwu, China.

The Figure 2 is one photography the Rhodochrosite stone, some cut and used with semi-precious jewelry.

The lovely rose-pink rock, Rhodochrosite, like its namesake the rose, is soft and fragile, measuring only 3.5 to 4 on the hardness, or Mohs scale. It is found in two forms: the first is a clear, bright pink, rhombohedra, gem quality crystal, which is rare and demands great skill from the cutter. The more common form, which comes from white banded stalactite rocks, is a little harder and is used for semi-precious jewellery $[13,14]$.

${ }^{\star}$ Correspondence to: Alireza Heidari, Faculty of Chemistry, California South University, 14731 Comet St. Irvine, CA 92604, USA, E-mail: Scholar.Researcher. Scientist@gmail.com; Alireza.Heidari@calsu.us; Central@aisi-usa.org

Key words: rhodochrosite, quartz crystal, hartree-fock methods, apt, mulliken, effective core potential, synchrotron radiation, cancer, tumoral tissues

Received: June 01, 2020; Accepted: June 16, 2020; Published: June 18, 2020 


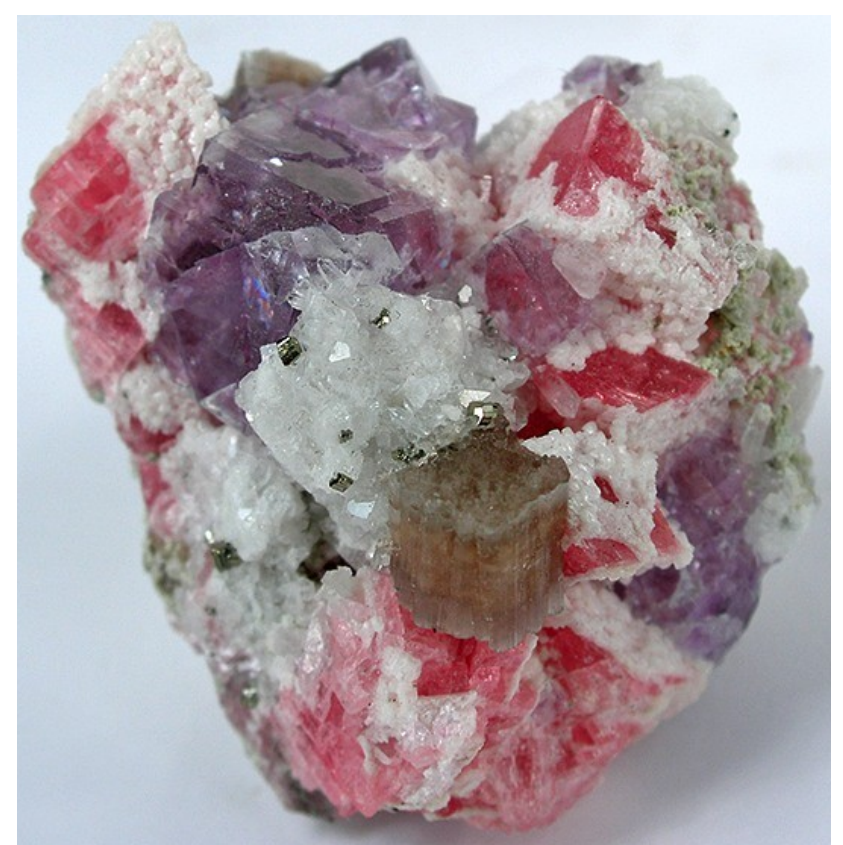

Figure 1. Rhodochrosite stone from China [13]

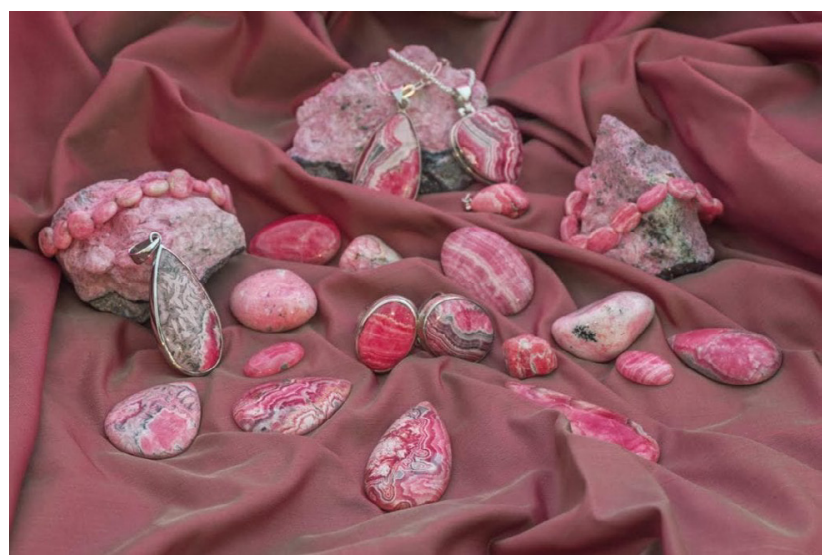

Figure 2. Some natural rhodochrosite rocks and others whipped and used with semiprecious jewels [14]

\section{Methods}

\section{Hartree-Fock Methods}

The molecular Hartree-Fock [15-21] wave function is written as an antisymmetrized product (Slater determinant) of spin-orbitals, each spin-orbital being a product of a spatial orbital $\phi_{i}$ and a spin function (either $\alpha$ or $\beta$ ).

The expression for the Hartree-Fock molecular electronic energy $E_{H F}$ is given by the variation theorem as $E_{H F}=\left\langle D\left|\hat{\mathrm{H}}_{\mathrm{el}}+\mathrm{V}_{\mathrm{NN}}\right| D\right\rangle$ where $\mathrm{D}$ is the Slater-determinant Hartree-Fock wave function and $\widehat{\boldsymbol{H}}_{\mathrm{el}}$ and $V_{N N}$ are given by

$$
\begin{gathered}
\left.\left.\hat{\boldsymbol{H}}_{\mathrm{el}}=-\frac{\cdot}{\sim}\right\rangle \nabla_{\mathrm{i}}^{2}-\right\rangle>\underline{-\alpha^{-}}+>>\underline{-} \\
V_{N N}=>>\underline{-u-p-}
\end{gathered}
$$

Since $V_{N N}$ does not involve electronic coordinates and $\boldsymbol{D}$ is normalized, we have $\left\langle D\left|V_{N N}\right| D\right\rangle=V_{N N}\langle D \mid D\rangle=V_{N N}$. The operator $\widehat{\boldsymbol{H}}_{\mathrm{el}}$ is the sum of one-electron operators $\hat{f}_{\mathrm{i}}$ and two-electron operators $\hat{g}_{i j}$; we have $\hat{\boldsymbol{H}}_{\mathrm{A}}=\sum_{i i} \hat{f}+\sum_{i} \sum_{i>i} \hat{g}_{i i}$, where $\hat{f}_{\mathrm{i}}=-\frac{1}{n} \nabla_{i}^{2} \Sigma_{\alpha} \Sigma_{\alpha} / r_{\mathrm{i} \alpha}$ and $\hat{g}_{i i}=1 / r_{\mathrm{i} i}$. The Hamiltonian $\widehat{\boldsymbol{H}}_{\mathrm{el}}$ is the same as the Hamiltonian $\widehat{\boldsymbol{H}}$ for an atom except that $\Sigma_{\alpha} \Sigma_{\alpha} / r_{\mathrm{i} \alpha}$ replaces $Z / r_{\mathrm{i}}$ in $f_{\mathrm{i}}$. Hence

$$
\left.\left.E=\langle D|\hat{\boldsymbol{H}}| D\rangle=2\rangle\left\langle\phi_{i}(1)\left|\hat{f}_{i}\right| \phi_{i}(2)\right\rangle+\right\rangle\right\rangle\left(2 \boldsymbol{J}_{i i}-\boldsymbol{K}_{i i}\right)
$$

where

$$
\begin{aligned}
& \boldsymbol{J}_{i i}=\left\langle\phi_{i}(1) \phi_{i}(2)\left|e^{\prime 2} / r_{12}\right| \phi_{i}(1) \phi_{i}(2)\right\rangle \\
& \text { and } \\
& \boldsymbol{K}_{i i}=\left\langle\phi_{i}(1) \phi_{i}(2)\left|e^{\prime 2} / r_{12}\right| \phi_{i}(1) \phi_{i}(2)\right\rangle \\
& \hat{f}_{i}=-\left(\hbar^{2} / 2 m_{e}\right) \nabla_{i}^{2}-Z e^{\prime 2} / r_{1}
\end{aligned}
$$

can be used to give $\left\langle D\left|\widehat{\boldsymbol{H}}_{\mathrm{el}}\right| D\right\rangle$.

Therefore, the Hartree-Fock energy of a diatomic or polyatomic molecule with only closed shells is

$$
\begin{aligned}
& \left.\left.\boldsymbol{E}_{H F}=2\right\rangle \boldsymbol{H}_{\mathrm{i}}^{\text {core }}+\right\rangle>\left(2 \boldsymbol{J}_{i i}-\boldsymbol{K}_{i j}\right)+\boldsymbol{V}_{N N}
\end{aligned}
$$

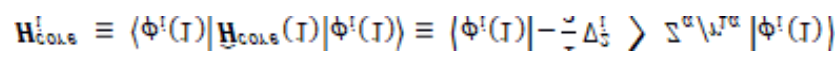

$$
\begin{aligned}
& \boldsymbol{J}_{i i} \equiv\left\langle\phi_{i}(1) \phi_{i}(2)\left|1 / r_{12}\right| \phi_{i}(1) \phi_{i}(2)\right\rangle \\
& \text { and } \\
& \boldsymbol{K}_{i i} \equiv\left\langle\phi_{i}(1) \phi_{i}(2)\left|1 / r_{12}\right| \phi_{i}(1) \phi_{i}(2)\right\rangle
\end{aligned}
$$

where the one-electron-operator symbol was changed from $\hat{f}_{\mathrm{i}}$ to $\widehat{H}^{\text {core }}(1) \cdot[5]$

\section{Mulliken Load}

Mulliken's loads are derived from the Mulliken population analysis and provide means for estimating partial atomic charges from numerical chemistry calculations, particularly those based on the linear combination of atomic orbitals. If the coefficients of the basic functions in the molecular orbital are $\boldsymbol{C}_{\boldsymbol{\mu}}$ for $\boldsymbol{\mu}^{e}$ the basic function $\boldsymbol{i}^{e}$ in the orbital molecular, the coefficients of the density matrix are:

$$
D_{\mu v}=2 \sum_{i} C_{\mu i} C_{v i}
$$

for a compact closed system in which each molecular orbital is doubly occupied. The population matrix $\boldsymbol{P}$ therefore has the following coefficients:

$$
P_{\mu v}=(D S)_{\mu v}
$$

$S$ is the overlay matrix for basic functions. The sum of the set of terms of $P_{\mu \nu}$ is $N$ - the total number of electrons. The Mulliken population analysis aims first of all to distribute the $\mathrm{N}$ electrons on all the basic functions. This is done by taking the diagonal elements of $P_{\mu v}$ and factorizing the non-diagonal elements equally between the two appropriate basic functions. Non-diagonal terms including $P_{\mu v}$ and $P_{v \mu}$ this simplifies the operation to a sum on a line. This defines the gross orbital population $(\mathrm{GOB})$ as:

$$
G O P_{\mu}=\sum_{v} P_{\mu v}
$$

The terms $G O P_{\mu}$ lie on $\mathrm{N}$ and then divide the total number of electrons between the basic functions. It then remains to sum these terms on all the basic functions of a given atom $\mathrm{A}$ in order to obtain the gross atomic population (GAP). The integral of the $\boldsymbol{G A P}_{\boldsymbol{A}}$ terms also gives $N$. The load, $Q_{A}$, is then defined as the difference between the number of electrons on the free isolated atom, which is the atomic number $Z_{A}$, and the raw atomic population: 


$$
Q_{A}=Z_{A}-G A P_{A}
$$

The problem with this approach is the even distribution of nondiagonal terms between the two basic functions. This leads to charge separations between the molecules that are exaggerated. Many other methods are used to determine atomic charges in molecules [22,23].

Concerning the nuclear contribution, the nuclear charge $Z_{A}$ can be written as $\boldsymbol{Z}_{\boldsymbol{A}}=\boldsymbol{q}_{\boldsymbol{A}}+\boldsymbol{Q}_{A}$, where $q_{A}$ and $Q_{A}$ account for the Mulliken net and gross atomic charge [22]. According to the Mulliken population analysis, the nuclear charge for $\boldsymbol{A}$ can be written as

$$
Z_{A}=q_{A}+\sum_{\mu} P_{\mu \mu} S_{\mu \mu}+\sum_{\mu<v} 2 P_{\mu v} S_{\mu v}+1 / 2 \sum_{B \neq A} \sum_{\mu}^{A} \sum_{v}^{B} 2 P_{\mu v} S_{\mu v}
$$

which upon substitution in the dipole moment expression yields

$$
\begin{array}{r}
\left\langle\hat{p}_{x}\right\rangle=-\sum_{A} \sum_{\mu} P_{\mu \mu} X_{A}-\sum_{A} \sum_{\mu<\nu} 2 P_{\mu \nu}\left\langle\phi_{\mu}|x| \phi_{\nu}\right\rangle-\sum_{A<\bar{B}} \sum_{\mu}^{A} \sum_{\nu}^{\bar{B}} 2 P_{\mu \nu}\left\langle\phi_{\mu}|x| \phi_{\nu}\right\rangle+\sum_{A} q_{A} X_{A} \\
+\sum_{A} \sum_{\mu} P_{\mu \mu} S_{\mu \mu} X_{A}+\sum_{A} \sum_{\mu<\nu} 2 P_{\mu \nu} S_{\mu \nu} X_{A}+1 / 2 \sum_{A \neq s} \sum_{\mu}^{A} \sum_{v}^{B} 2 P_{\mu \nu} S_{\mu \nu} X_{A}
\end{array}
$$

Note that $S_{\mu v} X_{A}=\left\langle\phi_{\mu}|x| \phi_{v}\right\rangle$ and $s_{\mu v}=1$ so that

$$
\left\langle\hat{p}_{x}\right\rangle=+\sum_{A} q_{A} X_{A}-\sum_{A} \sum_{\mu<v} 2 P_{\mu v} S_{\mu v} \bar{x}_{\mu v}^{A}-\sum_{A<B} \sum_{\mu}^{A} \sum_{\nu}^{B} 2 P_{\mu \nu} \bar{x}_{\mu v}^{A B}
$$

where

$$
\bar{x}_{\mu v}^{A}=\left\langle\phi_{\mu}\left|x-X_{A}\right| \phi_{v}\right\rangle
$$

and

$$
\bar{x}_{\mu v}^{A B}=\left\langle\phi_{\mu}\left|x-\frac{X_{A+} X_{B}}{2}\right| \phi_{v}\right\rangle
$$

The first two terms in eq. for $\left\langle\hat{p}_{x}\right\rangle$ are of atomic origin where the first one, involving the net atomic charge, is the only term with a classical counterpart. The second term resembles Coulson's atomic dipole, and the integral $\bar{x}_{\mu v}^{A}$ is the distance from the centroid of the hybrid orbital to nucleus A. For the third term, the integral $\bar{x}_{\mu \nu}^{A B}=$ is the distance of the center of charge from the midpoint of the chemical bond $\boldsymbol{A}-\boldsymbol{B}$. This contribution to the dipole moment has been referred to as the homopolar dipole [22] by Mulliken. As can be seen, the dipole moment has been partitioned into three contributions: the net atomic charge, the atomic dipole, and the homopolar dipole. Since the density matrix is invariant with respect to the choice of origin and since the sum of all net atomic charges vanishes, this partitioning of the dipole moment does not depend on the choice of origin for the system $[5,24]$.

\section{Atomic Polar Tensor (APT)}

One of the most useful methods for interpreting and predicting infrared intensities comes from the atomic polar tensor (APT) formalism $[25,26]$. In the APT framework, the derivative of the molecular dipole moment vector with respect to the $i$ th normal coordinate (which is directly related to the infrared intensity of the $i$ th fundamental mode), can be expressed as

$$
\frac{\partial p}{\partial Q_{i}}=\sum_{\alpha} \sum_{\xi} \frac{\partial p}{\partial \xi_{i}}\left[A U^{-1} L\right]_{\xi \alpha, i}
$$

For each atom $\alpha$ in molecule, the quantities $\partial p_{\tau} / \partial \xi_{\alpha}=\boldsymbol{P}_{\tau \xi}$ where $\tau=x, y, z$ and $\xi=X, Y, Z$ form the APT, represent by a $3 \times 3$ matrix $\boldsymbol{P}_{x}^{(\alpha)}$

$$
\boldsymbol{P}_{x}^{(\alpha)}=\nabla_{\alpha} \boldsymbol{p}
$$

So, if all the experimental infrared intensities and normal coordinates are known as well as the permanent dipole moment for a given molecule, the APT can be determined. On the other hand, these APTs can also be calculated by the SCF method and used to predict infrared intensities. These intensities can then be interpreted by partitioning the APT. This has been done before in the "charge-charge flux-overlap" (CCFO) model, first introduced by King and Mast $[27,28]$ and later applied by Person et al [29].

The general expression for the APT is:

$$
\nabla_{\alpha} p=q_{\alpha} \mathrm{E}+\sum_{A}\left(\nabla_{\alpha} \mathrm{q}_{A}\right) \boldsymbol{R}_{\mathrm{A}}-\sum_{A} \sum_{\mu<\nu} \nabla\left(2 P_{\mu \nu} \bar{R}_{\mu v}^{A}\right)-\sum_{A<B} \sum_{\mu}^{A} \sum_{\nu}^{\bar{B}} 2 P_{\mu \nu} \bar{x}_{\mu \nu}^{A B}
$$

where $\boldsymbol{E}$ is the identity matrix and each term of the APT is represented by a 3 X 3 matrix. The four contributions in the above equation can be identified according to Person, Coulson, and Mulliken terminology as charge, charge flux, atomic dipole flux, and homopolar dipole flux. Comparing with the CCFO model, the difference introduced in this work lies in the fact that the overlap term has been decomposed into two flux contributions (atomic dipole and homopolar dipole fluxes).

In eq. for $\nabla_{\alpha} p$, the first two terms are the only classical contributions, one of them being the Mulliken net charge of atom a in its equilibrium position, $\boldsymbol{R}_{\alpha}$, and the other being the "charge flux" corresponding to charge migration as the chemical bond involving the $\alpha$ atom has been distorted. The sum over all atoms, $\boldsymbol{A}$, implies there is electronic density deformation involving all the atoms in the molecule. These two terms have already been well discussed by Person, Zilles, and other [29-31] The atomic dipole flux can be separated into two parts if the gradient of the density matrix and center of charge integrals are taken inside the parentheses:

$$
-\sum_{\mu<\nu}^{\alpha} 2 P_{\mu \nu} \nabla_{\alpha}\left(\overline{\boldsymbol{R}}_{\mu v}^{A}\right)
$$

and

$$
-\sum_{A} \sum_{\mu<\nu}^{A} 2\left(P_{\mu \nu} \nabla_{\alpha}\right) \bar{R}_{\mu \nu}^{A}
$$

the first of the two terms in equation

$$
-\sum_{A} \sum_{\mu<\nu}^{A} 2\left(P_{\mu \nu} \nabla_{\alpha}\right) \overline{\boldsymbol{R}}_{\mu \nu}^{A}
$$

involves only the atom for which the APT is being calculated because only these $\phi_{s}^{\prime}$ depend on $\left(\boldsymbol{r}-\boldsymbol{R}_{\alpha}\right)$.

\section{Results and discussion}

The Figure 3 show on cell structure of a protonated rhodochrosite crystal of structure Stoichiometric is $\mathrm{CH}_{19} \mathrm{Mn}_{6} \mathrm{O}_{8}$, obtained after molecular dynamics via unrestricted Hartree-Fock method, in basis set CEP-4G, CEP-31G and CEP-121G [32-97]. 


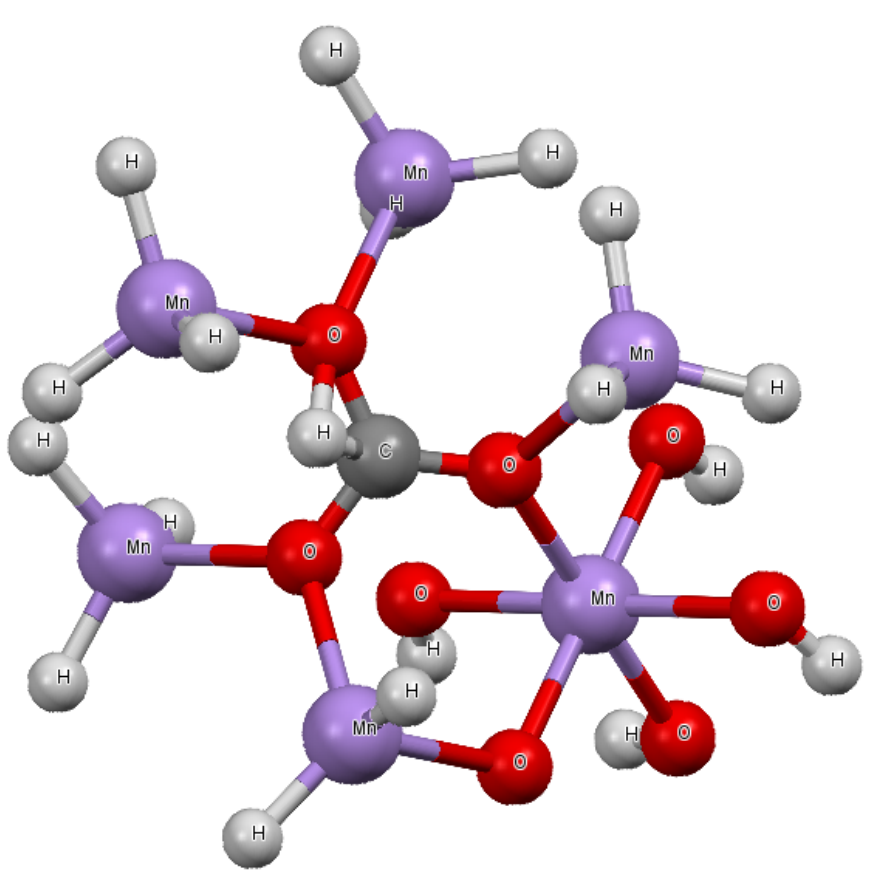

Figure 3. Cell structure of a protonated rhodochrosite crystal. Represented in red the oxygen; Purple in color Manganese; in gray color Hydrogen; in dark grey color the Carbon. Stoichiometry: $\mathrm{CMn}_{6} \mathrm{O}_{8}$. Stoichiometry protonated: $\mathrm{CH}_{19} \mathrm{Mn}_{6} \mathrm{O}_{8}$

The rhodochrosite crystal unit cell of structure $\mathrm{CMn}_{6} \mathrm{O}_{8}$, where the load distribution by the molecule was verified in the unrestricted Hartree-Fock method, UHF CEP-4G (Effective core potential (ECP) minimal basis), UHF CEP-31G (ECP split valance) and UHF CEP$121 \mathrm{G}$ (ECP triple-split basis), through the analysis of APT and Mulliken loads [98-100].

The rhodochrosite unit cell was protonated, then presented the structure $\mathrm{CH}_{19} \mathrm{Mn}_{6} \mathrm{O}_{8}$ for the study with ab initio methods with +4 multiplicity. The displacement of charges by the molecule was analyzed to verify the site of molecular action.

The load distribution by the protonated crystal is evaluated in Table 1 , and its vibrational frequencies in Table 2.

The largest load variation in the APT and Mulliken methods were obtained in the CEP-121G base set, with $\delta=2.922$ e $\delta=2.650$, respectively, being $\delta_{\mathrm{APT}}>\delta_{\text {Mulliken }}$, in all sets of calculated bases, Table 1 .

The Table 2 show the maximum absorbance peaks in the CEP-4G, CEP-31G and CEP-121G set basis are present at the frequencies 2172.23 $\mathrm{cm}^{-1}$, with a normalized intensity of $65 \% ; 2231.4 \mathrm{~cm}^{-1}$ and $45.4 \%$; and $2177.24 \mathrm{~cm}^{-1}$ and $100 \%$, respectively.

\section{Analysis}

The Mulliken load method in the UHF-CEP-4G base set; UHFCEP-31G and UHF-CEP-121G are sufficient to show that the sites of action of the rhodochrosite crystal structure are found in three Oxygen-linked Manganese atoms, which are attached to the central Carbon atom, as well as these. Oxygen atoms and the central Carbon.

These Manganese atoms show a slight negative to neutral load shift in the CEP-4G set basis, neutral to positive in the CEP-31G and CEP$121 \mathrm{G}$ set basis at the Mulliken charges, Figure 4.
The charge displacement is strong in the oxygen atoms, especially those near the central carbon, with negative load in all set basis studied, both in the APT and Mulliken charges.

The central carbon atom on all set basis is positively charged in both APT and Mulliken load, except Milliken in CEP-31G, which is neutral.

As might be expected from the charges by APT, the strong positive load manganese atoms, the strong negative load oxygen, the positively charged carbon atom. The manganese atom farthest from the carbon atom has a slight positive to neutral load shift.

The Mulliken load method presents a better result when compared to the APT, in the studied set basis, for protonated rhodochrosite crystal, with a smaller load variation $\delta=2,650$ u.a for CEP-121G.

The absorption peaks are in a Gaussian between the frequencies $1620 \mathrm{~cm}^{-1}$ and $2520 \mathrm{~cm}^{-1}$, Figure 3D.

The largest load variation in the APT and Mulliken methods were obtained in the CEP-121G base set, with $\delta=2.922$ e $\delta=2.650$, respectively, being $\delta_{\mathrm{APT}}>\delta_{\text {Mulliken }}$, in all sets of calculated basis, Table 1 .

The Figure 1 is one photography the Rhodochrosite stone from China.

The Figure 2 is one photography the Rhodochrosite stone, some cut and used with semi-precious jewelry.

The Figure 3 represented a Cell structure of a protonated rhodochrosite crystal. Represented in red the oxygen; silver in color Manganese; in gray color Hydrogen; in light see green color the Carbon. Stoichiometry not protonated: $\mathrm{CMn}_{6} \mathrm{O}_{8}$. Stoichiometry protonated: $\mathrm{CH}_{19} \mathrm{Mn}_{6} \mathrm{O}_{8}$.

The Figure 4 show the protonated rhodochrosite crystal for UHFCEP-4G basis set, UHF-CEP-31G and UHF-CEP-121G, respectively, which are shown in Table 2.

The rhodochrosite crystal unit cell of structure $\mathrm{CMn}_{6} \mathrm{O}_{8}$, where the load distribution by the molecule was verified in the unrestricted Hartree-Fock method, UHF CEP-4G (Effective core potential (ECP) minimal basis), UHF CEP-31G (ECP split valance) and UHF CEP$121 \mathrm{G}$ (ECP triple-split basis), through the analysis of APT and Mulliken loads.

Table 1. Load shifting on given basis sets of the Mulliken and APT method

\begin{tabular}{|c|c|c|c|c|c|c|}
\hline Basis Sets & \multicolumn{3}{|c|}{ Mulliken } & \multicolumn{3}{c|}{ APT } \\
\hline & \multicolumn{2}{|c|}{ Charge* $^{*}$} & $\boldsymbol{\delta}$ & \multicolumn{2}{c|}{ Charge* $^{*}$} & $\boldsymbol{\delta}$ \\
\hline CEP-4G & -1.064 & +1.064 & 2.128 & -1.366 & +1.366 & 2.732 \\
\hline CEP-31G & -1.034 & +1.034 & 2.068 & -1.362 & +1.362 & 2.724 \\
\hline CEP-121G & -1.325 & +1.325 & 2.650 & -1.461 & +1.461 & 2.922 \\
\hline
\end{tabular}

Table 2. Peaks maximum absorption intensity by the frequency given. Absorbance frequency as a function of vibrational frequencies of protonated rhodochrosite crystal for UHF-CEP-4G basis set, UHF-CEP-31G and UHF-CEP-121G

\begin{tabular}{|c|c|c|c|c|c|c|c|c|}
\hline & $\mathbf{v}\left(\mathbf{c m}^{-1}\right)$ & $\mathbf{I}(\mathbf{\%})$ & $\mathbf{v}\left(\mathbf{c m}^{-1}\right)$ & $\mathbf{I}(\mathbf{\%})$ & $\mathbf{v}\left(\mathbf{c m}^{-1}\right)$ & $\mathbf{I ~ ( \% )}$ & $\mathbf{v}\left(\mathbf{c m}^{-1}\right)$ & $\mathbf{I}(\mathbf{\%})$ \\
\hline CEP-4G & 2172.23 & 64.9904 & 2043.25 & 51.7671 & 2193.1 & 41.6608 & 2242.97 & 36.4643 \\
\hline $\begin{array}{c}\text { CEP- } \\
\text { 31G }\end{array}$ & 2231.4 & 45.3589 & 1891.26 & 41.6207 & 2027.77 & 40.3978 & 1926.32 & 38.0064 \\
\hline $\begin{array}{c}\text { CEP- } \\
121 G\end{array}$ & 2177.24 & 100 & 2261.98 & 87.0553 & 1947.03 & 83.1151 & 1778.57 & 51.6624 \\
\hline
\end{tabular}

$v=$ Frequency $\left(\mathrm{cm}^{-1}\right) ; \mathrm{I}=$ Normalized Intensity $(\%)$ 

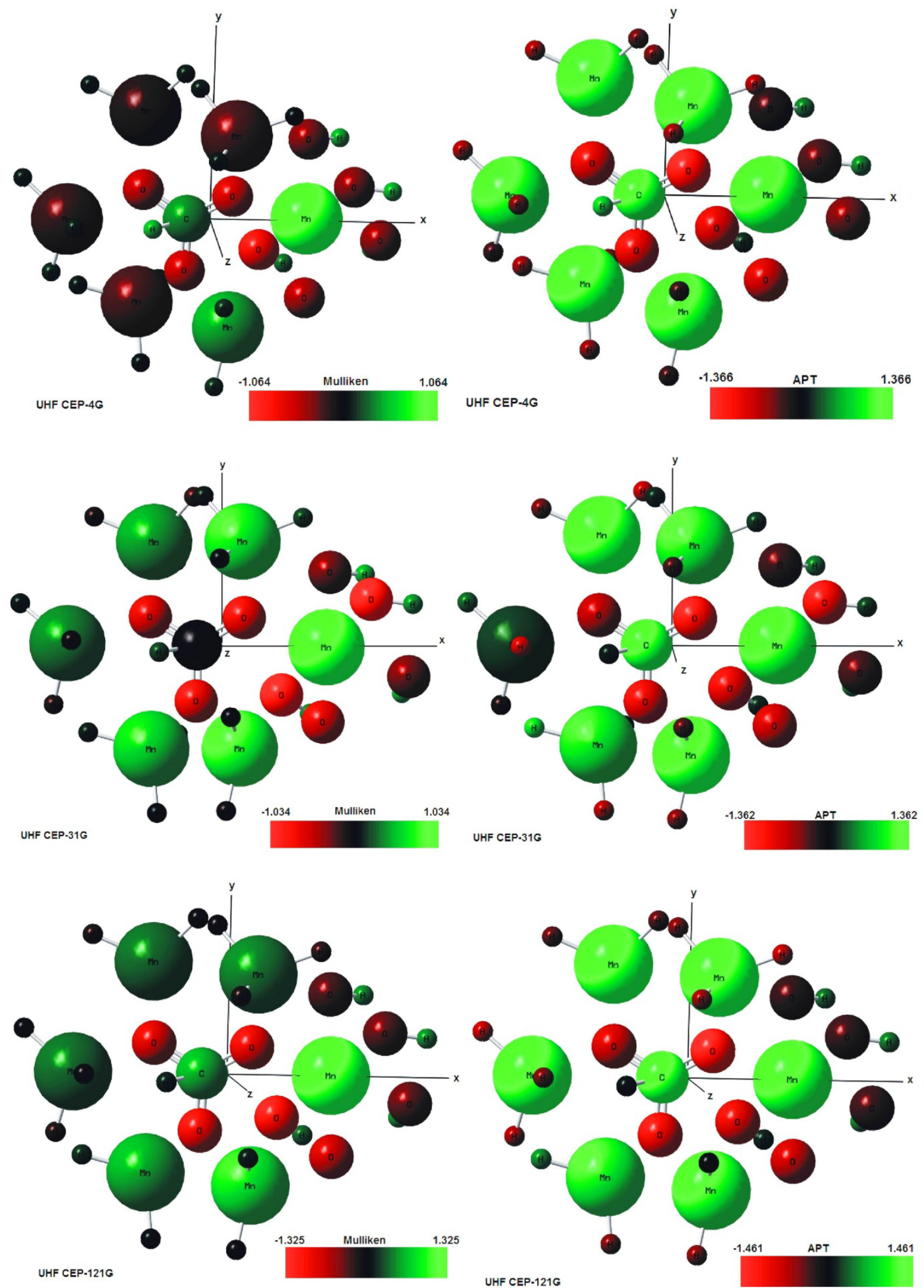

Figure 4. UHF-CEP-4G; UHF-CEP-31G and UHF-CEP-121G for APT and Mulliken 


\section{Conclusion}

The absorption peaks are in a Gaussian between the frequencies $1620 \mathrm{~cm}^{-1}$ and $2520 \mathrm{~cm}^{-1}$.

The Mulliken load method presents a better result when compared to the APT, in the studied set basis, for protonated rhodochrosite crystal, with a smaller load variation $\delta=2,650$ u.a for CEP-121G.

The maximum absorbance peaks in the CEP-4G, CEP-31G and CEP-121G set basis are present at the frequencies $2172.23 \mathrm{~cm}^{-1}$, with a normalized intensity of $0.65,2231.4 \mathrm{~cm}^{-1}$ and 0.454 and $2177.24 \mathrm{~cm}^{-1}$ and 1.0 respectively.

Later studies could check the advantages and disadvantages of rhodochrosite in the treatment of cancer through synchrotron radiation, such as one oscillator crystal.

An in-depth study is necessary to verify the absorption by the tumoral and non-tumoral tissues of rhodochrosite, before and after irradiating of synchrotron radiation using Small-Angle X-Ray Scattering (SAXS), Ultra-Small Angle X-Ray Scattering (USAXS), Fluctuation X-Ray Scattering (FXS), Wide-Angle X-Ray Scattering (WAXS), Grazing-Incidence Small-Angle X-Ray Scattering (GISAXS), Grazing-Incidence Wide-Angle X-Ray Scattering (GIWAXS), SmallAngle Neutron Scattering (SANS), Grazing-Incidence Small-Angle Neutron Scattering (GISANS), X-Ray Diffraction (XRD), Powder XRay Diffraction (PXRD), Wide-Angle X-Ray Diffraction (WAXD), Grazing- Incidence X-Ray Diffraction (GIXD) and Energy-Dispersive X-Ray Diffraction (EDXRD).

\section{References}

1. F. James Holler, Douglas A. Skoog and Stanley R. Crouch. Principles of Instrumental Analysis (6th ed.). Cengage Learning. 200, p. 9. ISBN 978-0-495-01201-6.

2. Fox Electronics. Quartz Crystal Theory of Operation and Design Notes. Oscillator Theory of Operation and Design Notes. 2008. Available in: April 16, 2019. URL: https://web.archive.org/web/20110725032851/http://www.foxonline.com/techdata. htm.

3. R. E. Newnham. Properties of materials. Anisotropy, Simmetry, Structure. Oxford University Press, New York, 2005.

4. C. D. Gribble and A. J. Hall. A Practical Introduction to Optical Mineralogy. 1985.

5. Creative Commons. (CC-BY 4.0). Wikipedia, The Free Encyclopedia, May 2019. URL: https://creativecommons.org/licenses/by/4.0/.

6. Ricardo Gobato, Marcia Regina Risso Gobato, Alireza Heidari. Rhodochrosite as Crystal Oscillator. Am J Biomed Sci \& Res. 2019 - 3 (2). AJBSR. MS. ID. 000659. DOI: 10.34297/AJBSR.2019.03.000659.

7. Ricardo Gobato, Marcia Regina Risso Gobato, Alireza Heidari. Calculation by UFF method of frequencies and vibrational temperatures of the unit cell of the rhodochrosite crystal International Journal of Advanced Chemistry, 7 (2) (2019) 77-81. doi: 10.14419 ijac.v7i1.29176.

8. Ricardo Gobato, Marcia Regina Risso Gobato, Alireza Heidari. Rhodochrosite as Crystal Oscillator. June 17, 2019. URL: https://www.researchgate.net/ publication/333817526 Rhodochrosite as Crystal Oscillator?enrichId=rgreq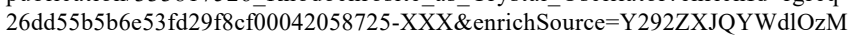 zMzgxNzUyNjtBUzo3NzA3NDE0MTkxMjY3ODRAMTU2MDc3MDQ4MjgwO$\mathrm{A} \% 3 \mathrm{D} \% 3 \mathrm{D} \& \mathrm{el}=1 \_\mathrm{x}$ 2\&_esc=publicationCoverPdf.

9. Ricardo Gobato, Marcia Regina Risso Gobato, Alireza Heidari. Rhodochrosite as Crystal Oscillator. Am J Biomed Sci \& Res. 2019 - 3(2). DOI: 10.34297/ AJBSR.2019.03.000659.

10. Ricardo Gobato, Marcia Regina Risso Gobato, Alireza Heidari. Rhodochrosite as Crystal Oscillator. viXra.org, Condensed Matter, viXra: 1908. 0295. http://vixra.org/ abs/1908.0295.

11. Ricardo Gobato, Marcia Regina Risso Gobato, Alireza Heidari, Abhijit Mitra. Rhodochrosite Optical Indicatrix. Peer Res Nest. 2019 - 1 (3). PNEST. 19.08.020.
12. Ricardo Gobato, Marcia Regina Risso Gobato, Alireza Heidari, Abhijit Mitra. Rhodochrosite Optical Indicatrix. viXra.org > Condensed Matter > viXra: 1908. 0455. URL: http://vixra.org/abs/1908.0455. Available in: Aug 22, 2019.

13. Rob Lavinsky, iRocks.com, CC-BY-SA-3.0. 2010. URL: https://de.wikipedia.org/wiki/ Rhodochrosit\#/media/Datei:Apatite-Rhodochrosite-Fluorite-169799.jpg. Available in: November 4, 2019.

14. Gemstone Qualities. Rhodochrosite. 2019. Available in: November 4, 2019. URL: https://www.roseheartjewels.co.uk/rhodochrosite/

15. N. Levine. Quantum Chemistry. Pearson Education (Singapore) Pte. Ltd., Indian Branch, 482 F. I. E. Patparganj, Delhi 110 092, India, 5th ed. edition, 2003.

16. Szabo and N. S. Ostlund. Modern Quantum Chemistry. Dover Publications, New York, 1989.

17. M. S. Gordon et al. General atomic and molecular electronic structure system (GAMESS). J. Comput. Chem., 14: 1347-1363, 1993.

18. K. Ohno, K. Esfarjani and Y. Kawazoe. Computational Material Science. SpringerVerlag, Berlin, 1999.

19. K. Wolfram and M. C. Hothausen. Introduction to DFT for Chemists. John Wiley \& Sons, Inc. New York, 2nd ed. edition, 2001.

20. P. Hohenberg and W. Kohn. Inhomogeneous electron gas. Phys. Rev., (136): B864 B871, 1964.

21. W. Kohn and L. J. Sham. Self-consistent equations including exchange and correlation effects. Phys. Rev., (140): A1133, 1965.

22. R. S. Mulliken, J. Chem. Phys. 1955 23, 1833-1840.

23. G. Csizmadia, Theory and Practice of MO Calculations on Organic Molecules, Elsevier, Amsterdam, 1976.

24. Ferreira, M. M. C. J. Phys. Chem. 1990, 94, 3220-3223.

25. Biarge, J. F.; Herranz, J.; Morcillo, J. An. R. Soc. Esp. Fis. Quim. Ser. A 1961, A57, 81.

26. Person, W. B.: Newton, J. H. J. Chem. Phys. 1974, 61. 1040.

27. King, W. T.; Mast, G. B. J. Phys. Chem. 1976,80,2521.

28. King, W. T. Vibrational Intensities in Infrared and Ramon Spectra: Person, W. B., Zerbi, G. Eds.; Elsevier: Amsterdam, 1982; Chapter 6.

29. Person, W. B.; Zilles, B.; Rogers, J. D.; Maia, R. G. A. J. Mol. Struct. 1982, 80, 297.

30. Zilles. B. A. Ph. D. Dissertation, University of Florida, 1980.

31. Zilles, B. A.; Person, W. 8. J. Chem. Phys. 1983, 79, 65.

32. Ricardo Gobato, Marcia Regina Risso Gobato, Alireza Heidari, Abhijit Mitra. "Hartree-fock Methods Analysis Protonated Rhodochrosite Crystal and Potential in the Elimination of Cancer Cells Through Synchrotron Radiation", Radiation Science and Technology. Vol. 5, No. 3, 2019, pp. 27-36. doi: 10.11648/j.rst.20190503.12.

33. Ricardo Gobato, Ibtihal Kadhim Kareem Dosh, Alireza Heidari, Abhijit Mitra, Marcia Regina Risso Gobato. "Perspectives on the Elimination of Cancer Cells Using Rhodochrosite Crystal Through Synchrotron Radiation, and Absorption the Tumoral and Non-Tumoral Tissues", Arch Biomed Eng \& Biotechnol. 3(2): 2019. ABEB. MS.ID.000558. DOI: 10.33552/ABEB.2019.03.000558.

34. M. S. Gordon and M. W. Schmidt. Advances in electronic structure theory: GAMESS a decade later. Theory and Applications of Computational Chemistry: the first forty years. Elsevier. C. E. Dykstra, G. Frenking, K. S. Kim and G. E. Scuseria (editors), pages 1167-1189, 2005. Amsterdam.

35. R. Gobato, A. Gobato, D. F. G. Fedrigo, "Inorganic arrangement crystal beryllium, lithium, selenium and silicon”. In XIX Semana da Física. Simpósio Comemorativo dos 40 anos do Curso de Física da Universidade Estadual de Londrina, Brazil, 2014. Universidade Estadual de Londrina (UEL).

36. R. Gobato, "Benzocaína, um estudo computacional", Master's thesis, Universidade Estadual de Londrina (UEL), 2008

37. R. Gobato, "Study of the molecular geometry of Caramboxin toxin found in star flower (Averrhoa carambola L.)". Parana J. Sci. Edu, 3 (1): 1-9, January 2017.

38. R. Gobato, A. Gobato, D. F. G. Fedrigo, "Molecular electrostatic potential of the main monoterpenoids compounds found in oil Lemon Tahiti - (Citrus Latifolia Var Tahiti)". Parana J. Sci. Edu., 1 (1): 1-10, November 2015. 
39. R. Gobato, D. F. G. Fedrigo, A. Gobato, "Allocryptopine, Berberine, Chelerythrine, Copsitine, Dihydrosanguinarine, Protopine and Sanguinarine. Molecular geometry of the main alkaloids found in the seeds of Argemone Mexicana Linn”. Parana J. Sci. Edu., 1 (2): 7-16, December 2015.

40. R. Gobato, A. Heidari, "Infrared Spectrum and Sites of Action of Sanguinarine by Molecular Mechanics and ab initio Methods", International Journal of Atmospheric and Oceanic Sciences. Vol. 2, No. 1, 2018, pp. 1-9. doi: 10.11648/j.jjaos.20180201.11.

41. R. Gobato, D. F. G. Fedrigo, A. Gobato, "Molecular geometry of alkaloids present in seeds of mexican prickly poppy". Cornell University Library. Quantitative Biology, Jul 15, 2015. arXiv: 1507. 05042.

42. R. Gobato, A. Gobato, D. F. G. Fedrigo, "Study of the molecular electrostatic potential of D-Pinitol an active hypoglycemic principle found in Spring flower Three Marys (Bougainvillea species) in the Mm+ method". Parana J. Sci. Educ., 2 (4): 1-9, May 2016.

43. R. Gobato, D. F. G. Fedrigo, A. Gobato, "Avro: key component of Lockheed X-35", Parana J. Sci. Educ., 1 (2): 1-6, December 2015.

44. R. Gobato, D. F. G. Fedrigo, A. Gobato, "LOT-G3: Plasma Lamp, Ozonator and CW Transmitter", Ciencia e Natura, 38 (1), 2016.

45. R. Gobato, "Matter and energy in a non-relativistic approach amongst the mustard seed and the faith. A metaphysical conclusion". Parana J. Sci. Educ., 2 (3): 1-14, March 2016.

46. R. Gobato, A. Gobato, D. F. G. Fedrigo, "Harnessing the energy of ocean surface waves by Pelamis System”, Parana J. Sci. Educ., 2 (2): 1-15, February 2016.

47. R. Gobato, A. Gobato, D. F. G. Fedrigo, "Mathematics for input space probes in the atmosphere of Gliese 581d”, Parana J. Sci. Educ., 2 (5): 6-13, July 2016.

48. R. Gobato, A. Gobato, D. F. G. Fedrigo, "Study of tornadoes that have reached the state of Parana”. Parana J. Sci. Educ., 2 (1): 1-27, 2016.

49. R. Gobato, M. Simões F. "Alternative Method of RGB Channel Spectroscopy Using a CCD Reader", Ciencia e Natura, 39 (2), 2017.

50. R. Gobato, A. Heidari, "Calculations Using Quantum Chemistry for Inorganic Molecule Simulation BeLi2SeSi", Science Journal of Analytical Chemistry, 5 (5): 76-85, September 2017.

51. M. R. R. Gobato, R. Gobato, A. Heidari, "Planting of Jaboticaba Trees for Landscape Repair of Degraded Area", Landscape Architecture and Regional Planning, 3 (1): 1-9, March 18, 2018.

52. R. Gobato, "The Liotropic Indicatrix", 2012, 114 p. Thesis (Doctorate in Pysics). Universidade Estadual de Londrina, Londrina, 2012.

53. R. Gobato, A. Heidari, "Calculations Using Quantum Chemistry for Inorganic Molecule Simulation BeLi2SeSi”, Science Journal of Analytical Chemistry, Vol. 5, No. 6, Pages 76-85, 2017.

54. R. Gobato, "O universo dos cristais líquidos", Cadernos PDE, Secretaria de Estado da Educação do Paraná., Vol. 2, Pages 1-15, 2009. ISBN 978-85-8015-053-7. www. diaadiaeducacao.pr.gov.br>2009_uel_fisica_md_ricardo_gobato.

55. R. Gobato, A. Heidari, "Molecular Mechanics and Quantum Chemical Study on Sites of Action of Sanguinarine Using Vibrational Spectroscopy Based on Molecular Mechanics and Quantum Chemical Calculations", Malaysian Journal of Chemistry, Vol. 20 (1), 1-23, 2018.

56. Heidari, R. Gobato. "A Novel Approach to Reduce Toxicities and to Improve Bioavailabilities of DNA/RNA of Human Cancer Cells-Containing Cocaine (Coke), Lysergide (Lysergic Acid Diethyl Amide or LSD), $\Delta 9$-Tetrahydrocannabinol (THC) [(-)-trans- $\Delta$ 9-Tetrahydrocannabinol], Theobromine (Xantheose), Caffeine, Aspartame (APM) (NutraSweet) and Zidovudine (ZDV) [Azidothymidine (AZT)] as Anti-Cancer Nano Drugs by Coassembly of Dual Anti-Cancer Nano Drugs to Inhibit DNA/RNA of Human Cancer Cells Drug Resistance”, Parana Journal of Science and Education, v. 4, n. 6, pp. 1-17, 2018.

57. Heidari, R. Gobato, "Ultraviolet Photoelectron Spectroscopy (UPS) and UltravioletVisible (UV-Vis) Spectroscopy Comparative Study on Malignant and Benign Human Cancer Cells and Tissues with the Passage of Time under Synchrotron Radiation", Parana Journal of Science and Education, v. 4, n. 6, pp. 18-33, 2018.

58. R. Gobato, A. Heidari, "Using the Quantum Chemistry for Genesis of a Nano Biomembrane with a Combination of the Elements Be, Li, Se, Si, C and H", J Nanomed Res., 7 (4): 241-252, 2018.

59. S. K. Agarwal, S. Roy, P. Pramanick, P. Mitra, R. Gobato, A. Mitra, "Marsilea quadrifolia: A floral species with unique medicinal properties", Parana J. Sci. Educ., v. 4, n. 5, (15-20), July 1, 2018.
60. Mitra, S. Zaman, R. Gobato. "Indian Sundarban Mangroves: A potential Carbon Scrubbing System”. Parana J. Sci. Educ., v. 4, n. 4, (7-29), June 17, 2018.

61. O. Yarman, R. Gobato, T. Yarman, M. Arik. "A new Physical constant from the ratio of the reciprocal of the "Rydberg constant" to the Planck length". Parana J. Sci. Educ., v. 4, n. 3, (42-51), April 27, 2018.

62. R. Gobato, M. Simões F., "Alternative Method of Spectroscopy of Alkali Metal RGB”, Modern Chemistry. Vol. 5, No. 4, 2017, pp. 70-74. https://doi:10.11648/j. mc.20170504.13.

63. D. F. G. Fedrigo, R. Gobato, A. Gobato, "Avrocar: a real flying saucer", Cornell University Library. 24 Jul 2015. arXiv: 1507.06916v1 [physics.pop-ph].

64. M, Simões F., A. J. Palangana, R. Gobato, O. R. Santos, "Micellar shape anisotropy and optical indicatrix in reentrant isotropic - nematic phase transitions", The Journal of Chemical Physics, 137, 204905 (2012); https://doi.org/10.1063/1.4767530.

65. Heidari, R. Gobato, "Putrescine, Cadaverine, Spermine and Spermidine-Enhanced Precatalyst Preparation Stabilization and Initiation (EPPSI) Nano Molecules", Parana Journal of Science and Education (PJSE)-v. 4, n. 5, (1-14) July 1, 2018

66. R. Gobato, A. Heidari, A. Mitra, "The Creation of C13H20BeLi2SeSi. The Proposal of a Bio-Inorganic Molecule, Using Ab Initio Methods for the Genesis of a Nano Membrane", Arc Org Inorg Chem Sci 3 (4). AOICS. MS. ID. 000167, 2018.

67. R. Gobato, A. Heidari, A. Mitra, "Using the Quantum Chemistry for Genesis of a Nano Biomembrane with a Combination of the Elements $\mathrm{Be}, \mathrm{Li}, \mathrm{Se}, \mathrm{Si}, \mathrm{C}$ and H", ResearchGate, See discussions, stats, and author profiles for this publication at: https:// www.researchgate.net/publication/326201181, 2018.

68. Heidari, R. Gobato, "First-Time Simulation of Deoxyuridine Monophosphate (dUMP) (Deoxyuridylic Acid or Deoxyuridylate) and Vomitoxin (Deoxynivalenol

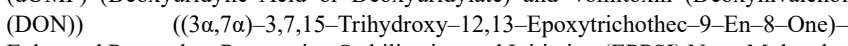
Enhanced Precatalyst Preparation Stabilization and Initiation (EPPSI) Nano Molecules Incorporation into the Nano Polymeric Matrix (NPM) by Immersion of the Nano Polymeric Modified Electrode (NPME) as Molecular Enzymes and Drug Targets for Human Cancer Cells, Tissues and Tumors Treatment under Synchrotron and Synchrocyclotron Radiations", Parana Journal of Science and Education, Vol. 4, No. 6, pp. 46-67, 2018.

69. R. Gobato, M. R. R. Gobato, A. Heidari, A. Mitra, "Spectroscopy and Dipole Moment of the Molecule C13H20BeLi2SeSi via Quantum Chemistry Using Ab Initio, HartreeFock Method in the Base Set CC-pVTZ and 6-311G**(3df, 3pd)", American Journal of Quantum Chemistry and Molecular Spectroscopy, Vol. 2, No. 1, pp. 9-17, 2018.

70. R. Gobato, M. R. R. Gobato, A. Heidari, "Raman Spectroscopy Study of the Nano Molecule C13H20BeLi2SeSi Using ab initio and Hartree-Fock Methods in the Basis Set CC-pVTZ and 6-311G** (3df, 3pd)", International Journal of Advanced Engineering and Science, Volume 7, Number 1, Pages 14-35, 2019.

71. Heidari, R. Gobato, "Evaluating the Effect of Anti-Cancer Nano Drugs Dosage and Reduced Leukemia and Polycythemia Vera Levels on Trend of the Human Blood and Bone Marrow Cancers under Synchrotron Radiation”, Trends in Res, Volume 2 (1): $1-8,2019$.

72. Heidari, R. Gobato, "Assessing the Variety of Synchrotron, Synchrocyclotron and LASER Radiations and Their Roles and Applications in Human Cancer Cells, Tissues and Tumors Diagnosis and Treatment", Trends in Res, Volume 2 (1): 1-8, 2019.

73. Heidari, R. Gobato, "Pros and Cons Controversy on Malignant Human Cancer Cells, Tissues and Tumors Transformation Process to Benign Human Cancer Cells, Tissues and Tumors", Trends in Res, Volume 2 (1): 1-8, 2019

74. Heidari, R. Gobato, "Three-Dimensional (3D) Simulations of Human Cancer Cells, Tissues and Tumors for Using in Human Cancer Cells, Tissues and Tumors Diagnosis and Treatment as a Powerful Tool in Human Cancer Cells, Tissues and Tumors Research and Anti-Cancer Nano Drugs Sensitivity and Delivery Area Discovery and Evaluation", Trends in Res, Volume 2 (1): 1-8, 2019.

75. Heidari, R. Gobato, "Investigation of Energy Production by Synchrotron, Synchrocyclotron and LASER Radiations in Human Cancer Cells, Tissues and Tumors and Evaluation of Their Effective on Human Cancer Cells, Tissues and Tumors Treatment Trend", Trends in Res, Volume 2 (1): 1-8, 2019.

76. Heidari, R. Gobato, "High-Resolution Mapping of DNA/RNA Hypermethylation and Hypomethylation Process in Human Cancer Cells, Tissues and Tumors under Synchrotron Radiation”, Trends in Res, Volume 2 (2): 1-9, 2019.

77. R. Gobato, M. R. R. Gobato, A. Heidari, "Storm Vortex in the Center of Paraná State on June 6, 2017: A Case Study", Sumerianz Journal of Scientific Research, Vol. 2, No. 2, Pages 24-31, 2019.

78. R. Gobato, M. R. R. Gobato, A. Heidari, "Attenuated Total Reflection-Fourier 
Transform Infrared (ATR-FTIR) Spectroscopy Study of the Nano Molecule C13H20BeLi2SeSi Using ab initio and Hartree-Fock Methods in the Basis Set RHF/ CC-pVTZ and RHF/6-311G** (3df, 3pd): An Experimental Challenge to Chemists", Chemistry Reports, Vol. 2, No. 1, Pages 1-26, 2019.

79. R. Gobato, M. R. R. Gobato, A. Heidari, A. Mitra, "New Nano-Molecule Kurumi$\mathrm{C} 13 \mathrm{H}$ 20BeLi2SeSi/C13H19BeLi2SeSi, and Raman Spectroscopy Using ab initio, Hartree-Fock Method in the Base Set CC-pVTZ and 6-311G** (3df, 3pd)", J Anal Pharm Res. 8 (1): 1-6, 2019.

80. R. Gobato, M. R. R. Gobato, A. Heidari, "Evidence of Tornado Storm Hit the Counties of Rio Branco do Ivaí and Rosario de Ivaí, Southern Brazil", Sci Lett 7 (1), 9 Pages, 2019.

81. Moharana Choudhury, Pardis Fazli, Prosenjit Pramanick, Ricardo Gobato, Sufia Zaman, Abhijit Mitra, "Sensitivity of the Indian Sundarban mangrove ecosystem to local level climate change", Parana Journal of Science and Education. Vol. 5, No. 3, 2019, pp. 24-28.

82. Arpita Saha, Ricardo Gobato, Sufia Zaman, Abhijit Mitra, "Biomass Study of Mangroves in Indian Sundarbans: A Case Study from Satjelia Island", Parana Journal of Science and Education. Vol. 5, No. 2, 2019, pp. 1-5.

83. Nabonita Pal, Arpan Mitra, Ricardo Gobato, Sufia Zaman, Abhijit Mitra, "Natural Oxygen Counters in Indian Sundarbans, the Mangrove Dominated World Heritage Site”, Parana Journal of Science and Education. Vol. 5, No. 2, 2019, pp. 6-13.

84. Ricardo Gobato, Victoria Alexandrovna Kuzmicheva, Valery Borisovich Morozov, -Einstein's hypothesis is confirmed by the example of the Schwarzschild problem", Parana Journal of Science and Education, Vol. 5, No. 1, 2019, pp. 1-6.

85. Sufia Zaman, Ricardo Gobato, Prosenjit Pramanick, Pavel Biswas, Uddalok Chatterjee, Shampa Mitra, Abhijit Mitra, "Water quality of the River Ganga in and around the city of Kolkata during and after Goddess Durga immersion", Parana Journal of Science and Education, Vol. 4, No. 9, 2018, pp. 1-7.

86. Ozan Yarman, Metin Arik, Ricardo Gobato, Tolga Yarman, Clarification of "Overall Relativistic Energy" According to Yarman's Approach.”, Parana Journal of Science and Education., v. 4, n. 8, 2018, pp. 1-10.

87. Sufia Zaman, Utpal Pal, Ricardo Gobato, Alekssander Gobato, Abhijit Mitra, "The Changing Trends of Climate in Context to Indian Sundarbans", Parana Journal of Science and Education, Vol. 4, No. 7, 2018, pp. 24-28.
88. Suresh Kumar Agarwal, Sitangshu Roy, Prosenjit Pramanick, Prosenjit Mitra, Ricardo Gobato and Abhijit Mitra. Parana Journal of Science and Education. Vol. 4, No. 5, 2018, pp. 15-20.

89. Ricardo Gobato and Marcia Regina Risso Gobato, "Evidence of Tornadoes Reaching the Countries of Rio Branco do Ivai and Rosario de Ivai, Southern Brazil on June 6, 2017’, Climatol Weather Forecasting 2018, 6: 4. DOI: 10.4172/2332-2594.1000242.

90. Ricardo Gobato. "New Nano-Molecule Kurumi and Raman Spectroscopy using ab initio, Hartree-Fock Method" Am J Biomed Sci \& Res. 2019-2 (4). AJBSR. MS. ID. 000594. DOI: 10.34297/AJBSR.2019.02.000594.

91. D. L. Graf, Rhodochrosite, Crystallographic tables for the rhombohedral carbonates, American Mineralogist 46 (1961) 1283-1316.

92. E. N. Maslen, V. A. Streltsov, N. R. Streltsova, N. Ishizawa, Electron density and optical anisotropy in rhombohedral carbonates. III. Synchrotron X-ray studies of $\mathrm{CaCO} 3, \mathrm{MgCO} 3$ and MnCO3, Acta Crystallographica B51 (1995) 929-939.

93. R. Wyckoff, The crystal structures of some carbonates of the calcite group, American Journal of Science 50 (1920) 317-360.

94. D. Marcus, D. E. Hanwell, D. C. Curtis, T. V Lonie, E. Zurek, G. R. Hutchison, "Avogadro: An advanced semantic chemical editor, visualization, and analysis platform" Journal of Cheminformatics 2012, 4: 17.

95. J. Cioslowski, Phys. Rev. Lett., 1989, 62, 1469.

96. Paul von Ragu Schleyer, Encyclopedia of computational chemistry, New York, J. Wiley, 1998.

97. Mulliken, R. S. "Electronic Population Analysis on LCAO-MO Molecular Wave Functions. I". The Journal of Chemical Physics. (1955). 23 (10): 1833-1840. Bibcode: 1955JChPh. 23.1833M. doi: 10.1063/1.1740588.

98. W. J. Stevens, H. Basch, and M. Krauss, "Compact effective potentials and efficient shared-exponent basis-sets for the 1st-row and 2nd-row atoms," J. Chem. Phys., 81 (1984) 6026-33. DOI: 10.1063/1.447604.

99. W. J. Stevens, M. Krauss, H. Basch, and P. G. Jasien, "Relativistic compact effective potentials and efficient, shared-exponent basis-sets for the 3rd-row, 4th-row, and 5throw atoms," Can. J. Chem., 70 (1992) 612-30. DOI: 10.1139/v92-085.

100. T. R. Cundari and W. J. Stevens, "Effective core potential methods for the lanthanides," J. Chem. Phys., 98 (1993) 5555-65. DOI: 10.1063/1.464902.

Copyright: $(2020$ Gobato R. This is an open-access article distributed under the terms of the Creative Commons Attribution License, which permits unrestricted use, distribution, and reproduction in any medium, provided the original author and source are credited. 